\title{
Hepatic microcirculatory failure ${ }^{1}$
}

\author{
Falência microcirculatória hepática
}

\author{
Fernando Silva Ramalho ${ }^{2}$, Izabel Fernandez-Monteiro ${ }^{3}$, Joan Rosello-Catafau ${ }^{4}$, Carmen Peralta $^{5}$ \\ 1. Work performed in the Liver Ischemia-Reperfusion Unit, Experimental Pathology Department, CSIC-IDIBAPS, Rosselló 161, 08036 \\ - Barcelona, Spain. \\ 2. PhD, Professor at the Department of Surgery and Anatomy, (FMRP-USP), Brazil, *Present address: Experimental Pathology Department, \\ IIBB-CSIC-IDIBAPS, Barcelona, Spain \\ 3. Ph.D. Student at the Liver Ischemia-Reperfusion Unit, Experimental Pathology Department, IIBB-CSIC, IDIBAPS, Barcelona, Spain \\ 4. PhD, Professor at the Liver Ischemia-Reperfusion Unit, Experimental Pathology Department, IIBB-CSIC, IDIBAPS, Barcelona, Spain \\ 5. PhD, Professor at the IDIBAPS, Barcelona, Spain
}

\begin{abstract}
Liver ischemia has been considered a frequent problem in medical practice, and can be associated to a number of surgical and clinical situations, such as massive hepatic resections, sepsis, liver trauma, circulatory shock and liver transplantation. After restoring blood flow, the liver is further subjected to an additional injury more severe than that induced by ischemia. On account of the complexity of mechanisms related to pathophysiology of ischemia and reperfusion (I/R) injury, this review deals with $\mathrm{I} / \mathrm{R}$ effects on sinusoidal microcirculation, especially when steatosis is present. Alterations in hepatic microcirculation are pointed as a main factor to explain lower tolerance of fatty liver to ischemia-reperfusion insult. The employment of therapeutic strategies that interfere directly with vasoactive mediators (nitric oxide and endothelins) acting on the sinusoidal perfusion seem to be determinant for the protection of the liver parenchyma against $\mathrm{I} / \mathrm{R}$. These approaches could be very suitable to take advantage of marginal specimens as fatty livers, in which the microcirculatory disarrangements hamper its employment in liver transplantation.
\end{abstract}

Key words: Liver Ischemia-Reperfusion Injury. Steatosis. Microcirculation.

\section{RESUMO}

A isquemia hepática é um problema relativamente freqüente na prática clínica, sobrevindo em situações diversas como ressecções hepáticas maciças, sepse, trauma hepático extenso, choque circulatório e transplante hepático. Durante a restauração do fluxo sanguíneo, o fígado é submetido a uma agressão adicional ainda mais intensa que aquela imposta pela isquemia. Devido à complexidade dos diversos mecanismos envolvidos na fisiopatologia da lesão por isquemia e reperfusão (I/R) hepática, esta revisão se limitará a discorrer sobre os efeitos da I/R na microcirculação sinusoidal, com ênfase para as alterações microvasculares que tomam lugar no fígado esteatótico pós-isquêmico. $\mathrm{O}$ desarranjo microcirculatório é apontado como um importante fator para explicar a reduzida tolerância do fígado esteatótico ao insulto isquêmico. $\mathrm{O}$ desenvolvimento de estratégias terapêuticas capazes de interferir diretamente com os mediadores vasoativos (óxido nítrico e endotelinas) relacionados ao déficit perfusional será determinante para a proteção do parênquima hepático frente às alterações induzidas pela $\mathrm{I} / \mathrm{R}$. Esses recursos seriam de especial interesse para o aproveitamento de fígados marginais, cuja falência microcirculatória compromete sobremaneira sua utilização para o transplante hepático.

Descritores: Isquemia-Reperfusão. Fígado Esteatótico. Microcirculação.

\section{Introduction}

Blood perfusion to previously ischemic tissue induces severe tissue injury, which is called ischemia-reperfusion (I/R) injury. ${ }^{1}$ In the liver, I/R injury can occur in several clinical settings such as hepatic trauma, resection of large intrahepatic tumors and liver transplantation1. Deprivation of oxygen to the liver during ischemia induces severe lesions but much more important ones are originated during reperfusion when oxygen entry to the organ is restored. On this case, an additional liver aggression occurs exacerbating greatly the previous injury induced by ischemia. ${ }^{2}$ Both facts lead to the induction of multiple and close related inflammatory processes in liver and extrahepatic organs which define the complex pathophysiology of I/R injury. This review deals with effects of $\mathrm{I} / \mathrm{R}$ syndrome on hepatic microcirculation, with special emphasis in the induced alterations in steatotic livers. 


\section{Ischemia and reperfusion injury}

The I/R injury is characterized by sinusoidal vasoconstriction, neutrophil accumulation, platelet aggregation and alterations on the capillary permeability leading to a progressive inflammatory reaction with important microcirculatory alterations, which can trigger diffuse cell death and consequent acute organ failure. ${ }^{1}$ The progression of I/R injury depends primarily on the presence of preexisting parenchymal alterations, such as hepatic steatosis and fibrosis, as well as the duration of ischemia period. ${ }^{3}$ When oxygen supply to hepatocytes becomes insufficient as result of reduced or absent blood flow, there is inhibition of the mitochondrial oxidative phosphorilation with the subsequent reduction in adenosine triphosphate (ATP) synthesis. Depletion of cellular ATP store induces alterations in transmembrane ion transport by inhibition of the ATP-dependent $\mathrm{Na}+\mathrm{K}+$ ATPase, leading to sodium and chloride influx changes, intracellular sodium accumulation, secondary alterationsin cellular calcium homeostasis and, particularly, cell swelling and death. ${ }^{4}$ It is well known that ischemic injury of the liver can be categorized into warm (or normothermic), cold (or hypotermic) injury, and rewarming. Whereas warm ischemia occurs in numerous surgical and clinical circumstances, as major hepatectomies, the coldstorage ischemia happens almost exclusively in liver transplantation. Rewarming ischemia typically occurs in liver transplantation during the period of implantation of the graft. ${ }^{5}$ Although the basic mechanisms of these injury categories are similar in all cases, also significant differences have been observed. Thus, the main site of injury in cold ischemia are nonparenchymal cells (sinusoidal endothelial, Kupffer, stellate and biliary epithelial cells), whereas in warm ischemia are hepatocytes. ${ }^{6}$ Rewarming ischemia seems also involve preferentially hepatocytes. In fact, cold ischemia is associated with reduced oxidative phosphorylation, lower cellular ATP levels, and increased glycolysis, while warm ischemia leads to greater mitochondrial dysfunction and oxidative stress. ${ }^{7}$ Although the direct ischemic insult determinates a significant damage to liver cells, the tissue injury originated during reperfusion is even so more severe. An excessive acute inflammatory response, which takes place promptly after blood flow restoring, has been recognized as key mechanism of liver injury during reperfusion period. ${ }^{8}$ Several studies with experimental models of warm and cold I/R injury have provided evidences that hepatic microcirculatory perfusion failure, activation of Kupffer cells, neutrophils, sinusoidal endothelial cells (SEC), CD4+ T lymphocytes, and subsequent generation of reactive oxygen species (ROS), cytokines and chemokines can be identified as most important episodes in the pathogenesis of this I/R syndrome. ${ }^{8}$ It is well assumed that the Kupffer cells, placed in the sinusoidal space, constitute the greatest fraction of resident macrophages in the whole body. Their activation has been considered as a central event in the pathophysiology of the early reperfusion injury both after warm and cold ischemia. ${ }^{8}$ Activation of Kupffer cells leads to the generation of ROS and other inflammatory mediators, such as the cytokines (TNF- $\alpha$, interleukin-1) and vasoactive mediators (nitric oxide, endothelins) as shown in Figure 1. During the first hours of reperfusion, ROS are generated by Kupffer cells, which can act directly as cytotoxins for the hepatocytes and the SEC, contributing to the progress of liver injury. Other additional sources of ROS are liver mitochondria and xanthine/xanthine oxidase system. ${ }^{8}$

\section{Microcirculatory Failure on Ischemia and Reperfusion Injury}

Liver microcirculation comprises a unique system of capillaries, called sinusoids, which are lined by a particular fenestrated endothelium with high permeability that allows maximum contact between hepatocytes and blood. ${ }^{9}$ Impairment of liver microcirculation is a main event in the development of hepatic I/R injury. ${ }^{10}$ It is well established that the severity of the microcirculatory disorders are closely correlated with the importance of applied I/R insult. ${ }^{11}$ The nature of the microcirculatory dysfunction after cold ischemia is quite similar that observed after warm ischemia. ${ }^{12}$ In the early phase of reperfusion (two hours after blood supply restoration), the breakdown of active transmembrane ion transport secondary to the ischemia-induced energy deficiency results in SEC vacuolization and swelling, as well as sinusoidal lumenal narrowing, being these factors responsible for the occurring microcirculation disorders during reperfusion. ${ }^{11}$ In addition to intracellular edema formation, it has been evidenced widening of the Disse's perisinusoidal space, microvascular accumulation of neutrophils, intravascular hemoconcentration, decreased erythrocyte velocity and extravasation of red blood cell due to loss of endothelial integrity. ${ }^{11}$ However, alterations in capillary vasoconstriction secondary to the imbalance between endothelins and NO levels (see below) seem to be the major contributing factor to the microcirculatory derangement during the reperfusion period. ${ }^{13}$ Active vasoconstriction induces progressive exclusion of sinusoids from perfusion, leading to an increase in the local heterogeneity of blood flow and oxygen supply. Indeed, this fact contributes to prolonging hypoxic period in entire liver lobules, exacerbating thus the tissue ischemic insult. ${ }^{10,11}$ In addition, microcirculatory disturbances may also be triggered by activation of the coagulation cascade and fibrin deposition during reperfusion. ${ }^{14}$ Although cellular ischemic damage is known to be most pronounced in the acinar pericentral zone (zone 3 ) after reperfusion, the most prominent sinusoidal perfusion failure was observed in periportal zone (zone1). ${ }^{11}$ This is a consequence of at least two facts: first, the lumenal narrowing due to SEC swelling primarily results in periportal microcirculatory deficit, since periportal sinusoids have normally smaller diameters with higher blood flow resistance when compared with pericentral sinusoids. ${ }^{15}$ Second, the major population of the Kupffer cells $(2 / 3)$ is located in the zone 1 , showing commonly a larger size than those ones situated in the zone $3 .{ }^{11}$ Initially, it was assumed that the accumulation and adhesion of neutrophils, as well as platelets, in the hepatic sinusoid could obstruct the lumen, originating disturbances of the microcirculation named as "no-reflow" phenomenon. ${ }^{16}$ However, later investigations argued against this hypothesis. Thus, during in vivo reperfusion, the sinusoidal neutrophil stasis was frequently evidenced, but these 


\section{LIVER ISCHEMIA-REPERFUSION INJURY}

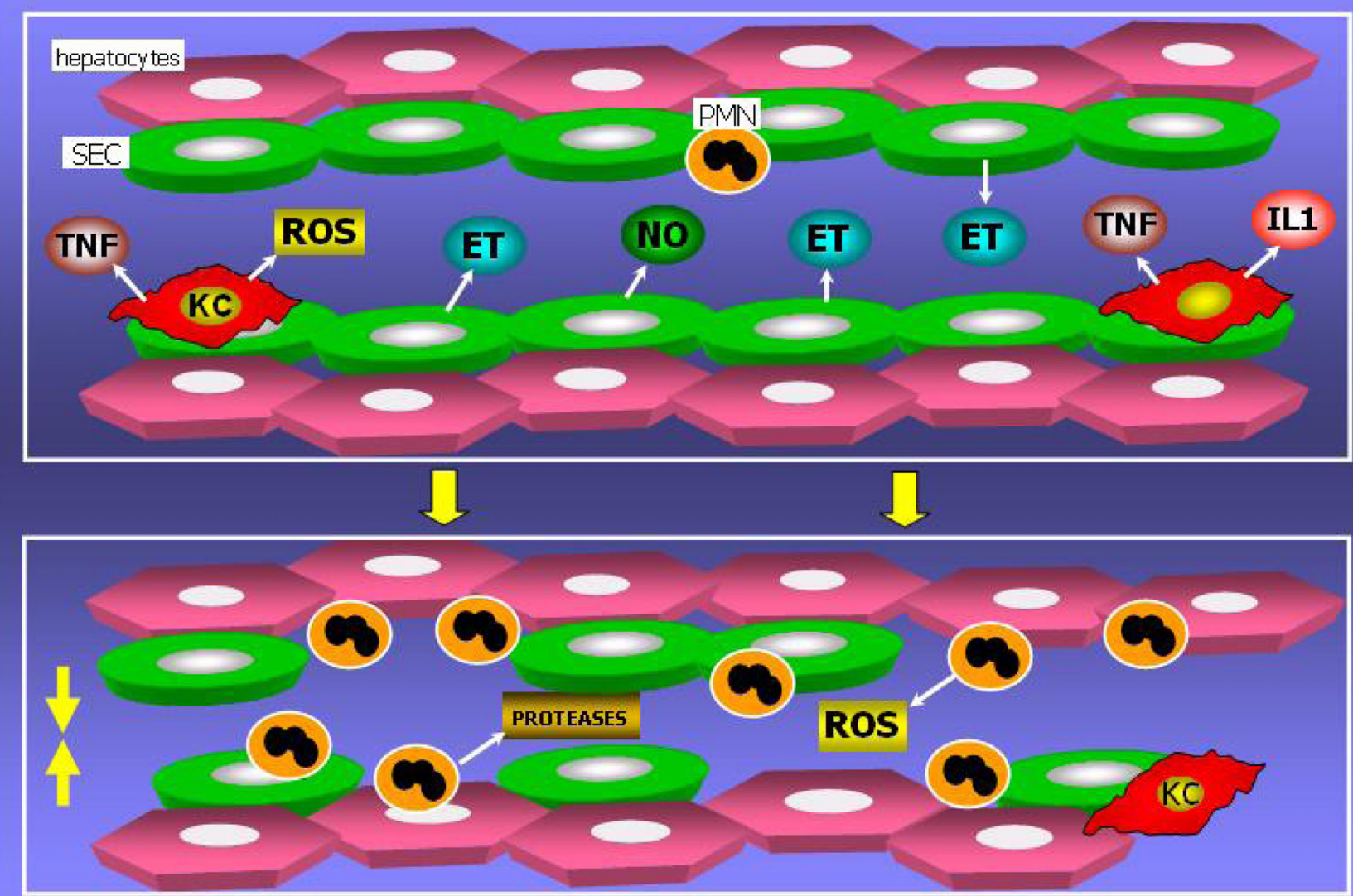

FIGURE 1 - Pathophysiological mechanisms of liver ischemia-reperfusion injury. Ischemia and reperfusion trigger activation of Kupffer cells (KC), which can generate reactive oxygen species (ROS) and cytokines TNF- $\alpha$ and IL-1. The imbalance between endothelins (ET) and nitric oxide (NO) produced by sinusoidal endothelial cells (SEC) leads to active vasoconstriction, narrowing of sinusoidal lumen and, the subsequent microcirculatory failure. TNF- $\alpha$ and IL-1 promotes neutrophil (PMN) activation, recruitment and transendothelial migration, which culminate in neutrophil-induced SEC and hepatocyte injury by releasing of ROS and proteases. Sinusoidal narrowing also contributes to hepatic neutrophil accumulation.

stagnant neutrophils did not necessarily occlude the capillary lumen. ${ }^{17}$ In addition, the microvascular neutrophil accumulation had not any effect on sinusoidal perfusion when an isolated perfused rat liver model was used. ${ }^{18}$ Recent investigations have corroborate that the main causative factor to impairment of postischemic microcirculation is the increased local synthesis of potent vasoconstrictor peptides, as endothelins (ETs), which are generated during earlier stages of reperfusion, being responsible for the reduction of sinusoidal diameter with the subsequent induction of microcirculatory derangements. ${ }^{13,19}$ This was confirmed by the fact that the intraportal infusion of ET-1 decreased the mean sinusoidal diameter and increased the heterogeneity of sinusoidal perfusion. Both effects are mainly produced by contraction of appendages of stellate cells that wrap around the sinusoids..$^{20}$ Moreover, pretreatments with anti-ET-1 antibody or ET receptor antagonist (bosentan) increased microcirculatory blood flow, attenuated tissue damage during reperfusion and improved survival. ${ }^{21,22}$ ETs are likely released by SEC, Kupffer and stellate cells in response to hypoxia, reactive oxygen species, proinflammatory cytokines and bacterial lipopolysaccharides (LPS). ${ }^{23}$ Gene expression of ETs receptor was found greatest on stellate cells, followed by SEC and Kupffer cells. ${ }^{24}$ Nitric oxide (NO) is a potent gaseous vasodilator involved in the regulation of hepatic microcirculation. Two major isoforms of NO synthase (NOS) are found in the liver, endothelial "constitutive" NOS (eNOS, NOS-3) and inducible NOS (iNOS, NOS-2). ${ }^{25}$ Endothelial NOS is expressed constitutively and exclusively in the SEC, and releases small amounts of NO for short periods of time. In contrast, iNOS synthesizes large amounts of NO for sustained periods, and can be transcriptionally up-regulated in all liver cells, e.g., hepatocytes, SEC, Kupffer and stellate cells, usually in response to inflammatory mediators. NO diffuses freely to adjacent cells and enters the cytosol, where it activates guanylate cyclase, resulting in an intracellular increase of cGMP levels. ${ }^{25}$ It is assumed that eNOS-derived NO production is protective in liver I/R injury through the regulation of sinusoidal diameter, prevention of neutrophil adhesion, inhibition of platelet aggregation and adhesion, and scavenging of reactive 
oxygen species. ${ }^{26}$ Moreover, NO derived from eNOS attenuates sinusoidal perfusion failure improving liver tissue oxygenation and finally counteracting the transient vasoconstrictor effects of ETs synthesized during earlier stages of reperfusion. ${ }^{27}$ The relevance of NO in hepatic microcirculation is supported by the fact that administration of eNOS inhibitors reduced microvascular perfusion and aggravated I/R injury, while the supplementation with Larginine (NO precursor) or NO donors improved microcirculatory status and minimized liver damage after I/ R. ${ }^{25}$ Results published in a recent paper using mice genetically modified deficient in either eNOS or iNOS suggest that eNOS, but not iNOS, plays an important role in downregulating $\mathrm{I} / \mathrm{R}$ injury during early reperfusion period. ${ }^{28}$ This is consistent with the fact that iNOS activation needs more time to be activated by different stimuli as proinflammatory cytokines and LPS. ${ }^{29,30}$ In any case, the benefits of iNOS activation in liver I/R seem to be controversial. ${ }^{31-33}$ Excessive NO production is detrimental because could be responsible for changes in systemic vascular tone and reactivity leading to hypotension and circulatory shock. In addition, the generation of peroxynitrite, a potent oxidant, formed by reacting $\mathrm{NO}$ with superoxide anion, could also cause cell injury through lipid peroxidation, direct inhibition of mitochondrial respiratory chain enzymes, inhibition of membrane $\mathrm{Na}+/ \mathrm{K}+$ ATPase activity, or oxidative protein modification such as formation of nitrotyrosine. ${ }^{2}$

\section{Hepatic Steatosis and Microcirculatory Failure}

Hepatic steatosis or fatty liver is the result of the abnormal accumulation of triacylglycerol within the cytoplasm of hepatocytes, with an incidence ranging from 6 to $11 \%$ in autopsies of accidental deaths in developed countries. ${ }^{34}$ The steatosis could be quantitatively classified according to the fat infiltration in the hepatocytes as mild (less than $30 \%$ of the hepatocytes have fat vacuoles within the cytoplasm), moderate (between 30 and $60 \%$ ) or severe (more than 60\%). ${ }^{35}$ Histologically, it is classified as macro and microvesicular steatosis. In macrovesicular steatosis, the hepatocytes are distended by a single large vacuole, which displaces the nucleus to one side. This is in general considered a benign and reversible condition. In the other hand, microvesicular steatosis is more serious and often associated with impairment of $\beta$-oxidation of lipids and inflammatory changes. In that case, multiple small droplets are finely dispersed in the cytoplasm without nuclear displacement. ${ }^{35}$ The more frequent causes of macro and microvesicular steatosis are pointed on the Chart 1. In 1987, Portman and cols. ${ }^{36}$ correlated, for the first time, the presence of steatosis and the primary graft failure. It is well established that steatosis represents a risk associated with the viability of the hepatic graft after liver transplantation, which could justify livers with more than $20 \%$ of steatosis being discarded. However, the lack of organs for transplantation obligates the utilization of grafts with moderate steatosis, beside it vulnerability for the I/R injury. ${ }^{37}$ In despite of the lack of clinic evidences of the mechanisms through which these two kinds of steatosis affect the I/R injury, recent investigations demonstrated that mouse macrosteatotic livers are more susceptible for the I/R injury than those with microsteatosis. ${ }^{34}$ It is well known that the triglycerides deposition as intracytoplasmic fat droplets is associated with an increase in hepatocellular volume, which may induce distortion and narrowing of sinusoid, with reduction of the luminal diameter by up to $50 \%$ compared with that in the normal liver. ${ }^{38}$ Consequently, increases in liver fat infiltration are consistent the apparition of severe

CHART 1 - Main causes of macro and microvesicular steatosis.

\begin{tabular}{|c|l|}
\hline Steatosis macrovesicular & Steatosis microvesicular \\
\hline Drugs / toxins & Acute fatty liver of pregnancy \\
Alcohol & Reye's syndrome \\
Drugs (corticosteroids, warfarin, & $\begin{array}{l}\text { Drugs } \\
\text { etc.) }\end{array}$ \\
Inherited metabolits disorders & Salicylate \\
Galactosemia & Tedracyclines \\
Hereditary fructose intolerance & Aflatoxins \\
Tyrosinemia & Mitochondrial cytopaties \\
Abetalipoproteinemia & \\
Other disorders & \\
Diabetes mellitus & \\
Obesity & \\
Protein calorie malnutrition & \\
Total parenteral nutrition & \\
Hyperlipidaemia & \\
\hline
\end{tabular}


alterations in liver blood flow and hepatic microcirculation, respectively. In this line, it has been suggested that sinusoidal perfusion alterations in macrovesicular steatosis, could be associated with a mechanical compression of the sinusoidal spaces by the steatosis and by the neutrophil swelling. ${ }^{38}$ The importance of the control of the balance between ETs/NO seems to be crucial for the sinusoidal perfusion regulation and consequently, for subsequent modulation of hepatic microcirculation disturbances in liver steatosis. ${ }^{35}$ Thus, the administration of L-arginine, a NO precursor, contributes for the microvascular perfusion in the fatty livers by increasing NO generation, which compensates the sinusoidal vasoconstriction induced by ETs, leading, thus, to the amelioration of microcirculatory disturbance associated with steatosis. ${ }^{34}$ Also, the importance of the ETs/NO balance confirmed by the application of surgical strategies, as ischemic preconditioning (IP), protects the liver from I/R injury. It is well established that liver IP stimulates the endogenous production of NO, whose inhibitory action on the ETs generated during reperfusion would explain the benefits of IP on the improvement of sinusoidal perfusion and tissue oxygenation ${ }^{34}$, respectively. Similar beneficial effects of NO generation on steatotic liver microcirculation have been described when steatotic liver grafts were conserved in IGL-1 solution. IGL-1 solution resulted in better preservation of fatty grafts when compared to the traditional University of Wisconsin solution. ${ }^{39}$ The advantages of IGL-1 seem to be associated with increased NO levels after cold preservation by activation of eNOS. This could compensate the vasoconstrictor effects of the ETs produced during cold ischemia, contributing, thus, to the amelioration of microcirculatory disorders. ${ }^{39}$ At last, it is important to remark that is necessary to explore new therapeutic strategies that interfering directly on ETs/NO balance for protecting microcirculation alterations induced in normal and fatty livers I/R injury. These approaches will be determinant to take advantage of marginal livers, as steatotic grafts, whose microcirculatory failure compromise its use for liver transplantation purposes.

\section{References}

1. Serracino-Inglott F, Habib NA, Mathie RT. Hepatic ischemia-reperfusion injury. Am J Surg. 2001; 181:160-6.

2. Glantzounis GK, Salacinski HJ, Yang W, Davidson BR, Seifalian AM. The contemporary role of antioxidant therapy in attenuating liver ischemia-reperfusion injury: a review. Liver Transpl. 2005;11:1031-47.

3. Isozaki H, Okajima K, Kobayashi M, Hara H, Akimoto H. Experimental study of liver injury after partial hepatectomy with intermittent or continuous hepatic vascular occlusion. Differences in tolerance to ischemia between normal and cirrhotic livers. Eur Surg Res. 1995;27:313-22.

4. Belzer FO, Southard JH. Principles of solid-organ preservation by cold storage. Transplantation. 1988;45: 673-6.

5. Selzner N, Rudiger H, Graf R, Clavien PA. Protective strategies against ischemic injury of the liver. Gastroenterology. 2003; 125: 917-36.
6. Ikeda T, Yanaga K, Kishikawa K, Kakizoe S, Shimada M, Sugimachi K. Ischemic injury in liver transplantation: difference in injury sites between warm and cold ischemia in rats. Hepatology. 1992;16: 454-61.

7. Mochida S, Arai M, Ohno A, Masaki N, Ogata I, Fujiwara $\mathrm{K}$. Oxidative stress in hepatocytes and stimulatory state of Kupffer cells after reperfusion differ between warm and cold ischemia in rats. Liver. 1994;14: 234-40.

8. Jaeschke H. Molecular mechanisms of hepatic ischemiareperfusion injury and preconditioning. Am J Physiol Gastrointest Liver Physiol. 2003;284: G15-26.

9. McCuskey RS. Morphological mechanisms for regulating blood flow through hepatic sinusoids. Liver. 2000; 20: 3-7.

10. Clemens MG, Zhang JX. Regulation of sinusoidal perfusion: in vivo methodology and control by endothelins. Semin Liver Dis. 1999; 19: 383-96

11. Vollmar B, Glasz J, Leiderer R, Post S, Menger MD. Hepatic microcirculatory perfusion failure is a determinant of liver dysfunction in warm ischemiareperfusion. Am J Pathol. 1994; 145: 1421-31.

12. Menger MD, Vollmar B. Role of microcirculation in transplantation. Microcirculation. 2000;7:291-306.

13. McCuskey RS, Urbaschek R, Urbaschek B. The microcirculation during endotoxemia. Cardiovasc Res. 1996;32: 752-63.

14. Arai M, Mochida S, Ohno A, Fujiwara K. Blood coagulation in the hepatic sinusoids as a contributing factor in liver injury following orthotopic liver transplantation in the rat. Transplantation. 1996;62: 1398-401.

15. Komatsu H, Koo A, Guth PH. Leukocyte flow dynamics in the rat liver microcirculation. Microvasc Res. 1990; 40: $1-13$.

16. Koo A, Komatsu H, Tao G, Inoue M, Guth PH, Kaplowitz N. Contribution of no-reflow phenomenon to hepatic injury after ischemia-reperfusion: evidence for a role for superoxide anion. Hepatology. 1992; 15: 507-14.

17. Vollmar B, Richter S, Menger MD. Leukocyte stasis in hepatic sinusoids. Am J Physiol. 1996; 270: G798-803.

18. Zhang JX, Jones DV, Clemens MG. Effect of activation on neutrophil-induced hepatic microvascular injury in isolated rat liver. Shock. 1994; 1: 273-8.

19. Nakamura S, Nishiyama R, Serizawa A, Yokoi Y, Suzuki $\mathrm{S}$, Konno H, Baba S, Muro H. Hepatic release of endothelin-1 after warm ischemia. Reperfusion injury and its hemodynamic effect. Transplantation. 1995; 59: 679-84.

20. Pannen BH. New insights into the regulation of hepatic blood flow after ischemia and reperfusion. Anesth Analg. 2002; 94: 1448-57.

21. Housset C, Rockey DC, Bissell DM. Endothelin receptors in rat liver: lipocytes as a contractile target for endothelin 1. Proc Natl Acad Sci U S A. 1993; 90: 9266-70.

22. Zhang JX, Bauer M, Clemens MG. Vessel- and target cell-specific actions of endothelin-1 and endothelin-3 in rat liver. Am J Physiol. 1995; 269: G269-77. 
23. Urakami A, Todo S, Zhu Y, Zhang S, Jin MB, Ishizaki N, Shimamura T, Totsuka E, Subbotin V, Lee R, Starzl TE. Attenuation of ischemic liver injury by monoclonal antiendothelin antibody, AwETN40. J Am Coll Surg. 1997; 185: 358-64.

24. Koeppel TA, Kraus T, Thies JC, Gebhard MM, Otto G, Post S. Effects of mixed ETA and ETB-receptor antagonist (Ro-47-0203) on hepatic microcirculation after warm ischemia. Dig Dis Sci. 1997; 42: 1316-21.

25. Shah V, Kamath PS. Nitric oxide in liver transplantation: pathobiology and clinical implications. Liver Transpl. 2003; 9:1-11.

26. Peralta C, Rull R, Rimola A, Deulofeu R, Rosello-Catafau J, Gelpi E, Rodes J. Endogenous nitric oxide and exogenous nitric oxide supplementation in hepatic ischemia-reperfusion injury in the rat. Transplantation. 2001; 71:529-36.

27. Pannen BH, Al-Adili F, Bauer M, Clemens MG, Geiger KK. Role of endothelins and nitric oxide in hepatic reperfusion injury in the rat. Hepatology. 1998; 27: 755-64.

28. Kawachi S, Hines IN, Laroux FS, Hoffman J, Bharwani S, Gray L, Leffer D, Grisham MB. Nitric oxide synthase and postischemic liver injury. Biochem Biophys Res Commun. 2000; 276: 851-4.

29. Hur GM, Ryu YS, Yun HY, Jeon BH, Kim YM, Seok JH, Lee JH. Hepatic ischemia/reperfusion in rats induces iNOS gene transcription by activation of NF-kappaB. Biochem Biophys Res Commun. 1999; 261: 917-22.

30. Grisham MB, Jourd'Heuil D, Wink DA. Nitric oxide. I. Physiological chemistry of nitric oxide and its metabolites:implications in inflammation. Am J Physiol. 1999; 276: G315-21.

31. Meguro M, Katsuramaki T, Nagayama M, Kimura H, Isobe M, Kimura Y, Matsuno T, Nui A, Hirata K. A novel inhibitor of inducible nitric oxide synthase (ONO-1714) prevents critical warm ischemia-reperfusion injury in the pig liver. Transplantation. 2002; 73: 1439-46.

32. Koeppel TA, Thies JC, Schemmer P, Trauner M, Gebhard MM, Otto G, Post S. Inhibition of nitric oxide synthesis in ischemia/reperfusion of the rat liver is followed by impairment of hepatic microvascular blood flow. J Hepatol. 1997; 27: 163-9.
33. Rivera-Chavez FA, Toledo-Pereyra LH, Dean RE, Crouch L, Ward PA. Exogenous and endogenous nitric oxide but not iNOS inhibition improves function and survival of ischemically injured livers. J Invest Surg. 2001; 14: 267-73.

34. Ijaz S, Yang W, Winslet MC, Seifalian AM. The role of nitric oxide in the modulation and tissue oxygenation in an experimentl model of hepatic steatosis. Microvasc Res. 2005; 70: 129-36

35. D'Alessandro A, Kalayoglu M, Sollinger H, Hoffmann RM, Reed A, Knechtle SJ, Pirsch JD, Hafez GR, Lorentzen D, Belzer FO. The predictive value of donor liver biopsies fort he development of primary nonfunction after orthotopic liver transplantation. Transplantation. 1991; 52:157-63.

36. Portmann B, Wight D. Pathology of liver transplantation. In: Calne R. Liver Transplantation. 1987. p 437.

37. Selzner M, Clavien PA. Fatty liver in liver transplantation and surgery. Semin Liver Dis. 2001; 21: 105-13.

38. Teramoto K, Bowers JL, Kruskal JB, Clouse ME. Hepatic microcirculatory changes after reperfusion in fatty and normal liver transplantation in the rat. Transplantation. 1993; 56: 1076-82.

39. Ben Mosbah I, Roselló-Catafau J, Franco-Gou R, Ben Abdennebi H, Ramella-Virieux S, Boillot O, Peralta C. Preservation of steatotic livers in IGL-1 solution. Liver Transplantation. 2006 (in press).

\section{Acknowledgements}

Supported by The Ministerio de Educación y Ciencia (Project grant $\mathrm{n}^{\mathrm{o}}$ BFI 2003-00912, SAF 2005-00385, and Ramón y Cajal research contract to Carmen Peralta) (Madrid, España), Ministerio de Asuntos Exteriores (HP2003-0051) and Generalitat de Catalunya (project 2005SGR/00781).

The authors thank to CAPES - Ministério da Educação (Brasília, Brasil) and to AECI/MAEC (Madrid, España) for the research support for F.S. Ramalho and I. FernandezMonteiro, respectively.

\section{Correspondence:}

Joan Roselló-Catafau.

Unidad de Isquemia y Reperfusión Hepática Experimental, Instituto de Investigaciones Biomédicas de Barcelona, IIBBCSIC-IDIBAPS, Rosselló $161,7^{\circ}$ planta.

08036 - Barcelona, Spain.

E-mail:jrcbam@iibb.csic.es

Conflict of interest: none Financial source: none.
icas de Barcelona, IIBB-

\section{How to cite this article:}

Ramalho FS, Fernandez-Monteiro I, Rosello-Catafau J, Peralta C. Hepatic microcirculatory failure. Acta Cir Bras. [serial on the Internet] 2006;21 Suppl 1. Available from URL: $\underline{\text { http://www.scielo.br/acb }}$ .

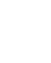

